\title{
Plasmon-free polymeric nanowrinkled substrates for surface-enhanced Raman spectroscopy of two-dimensional materials
}

Marziye Mirbagheri, Ph.D.**, ${ }^{\dagger,+, \boldsymbol{q}, \S}$ Jasneet Kaur, Ph.D. ${ }^{* *},{ }^{\dagger}$ Hoang Vu Pham, ${ }^{\dagger,+,}$ Vahid Adibnia, Ph.D., ${ }^{\S}$ Hadis Zarrin, Ph.D., ${ }^{\dagger}$ Xavier Banquy, Ph.D., ${ }^{\S}$ and Dae Kun Hwang, Ph.D.*,†,,

$\dagger$ Department of Chemical Engineering, Faculty of Engineering 85 Architectural Science, Ryerson University, Toronto, Ontario M5B 2K3, Canada

$\ddagger$ Keenan Research Center, Li Ki Shing Knowledge Institute, St. Michael’s Hospital, Toronto, Ontario M5B 1W8, Canada

IInstitute for Biomedical Engineering, Science and Technology (iBEST), St. Michael's Hospital, Toronto, Ontario M5B 1W8, Canada §Faculty of Pharmacy, Université de Montréal, C.P. 6128, succursale Centre Ville, Montreal, Quebec H3C 3J7, Canada

E-mail: dkhwang@ryerson.ca

* Corresponding author

** These authors equally contributed to this work. 


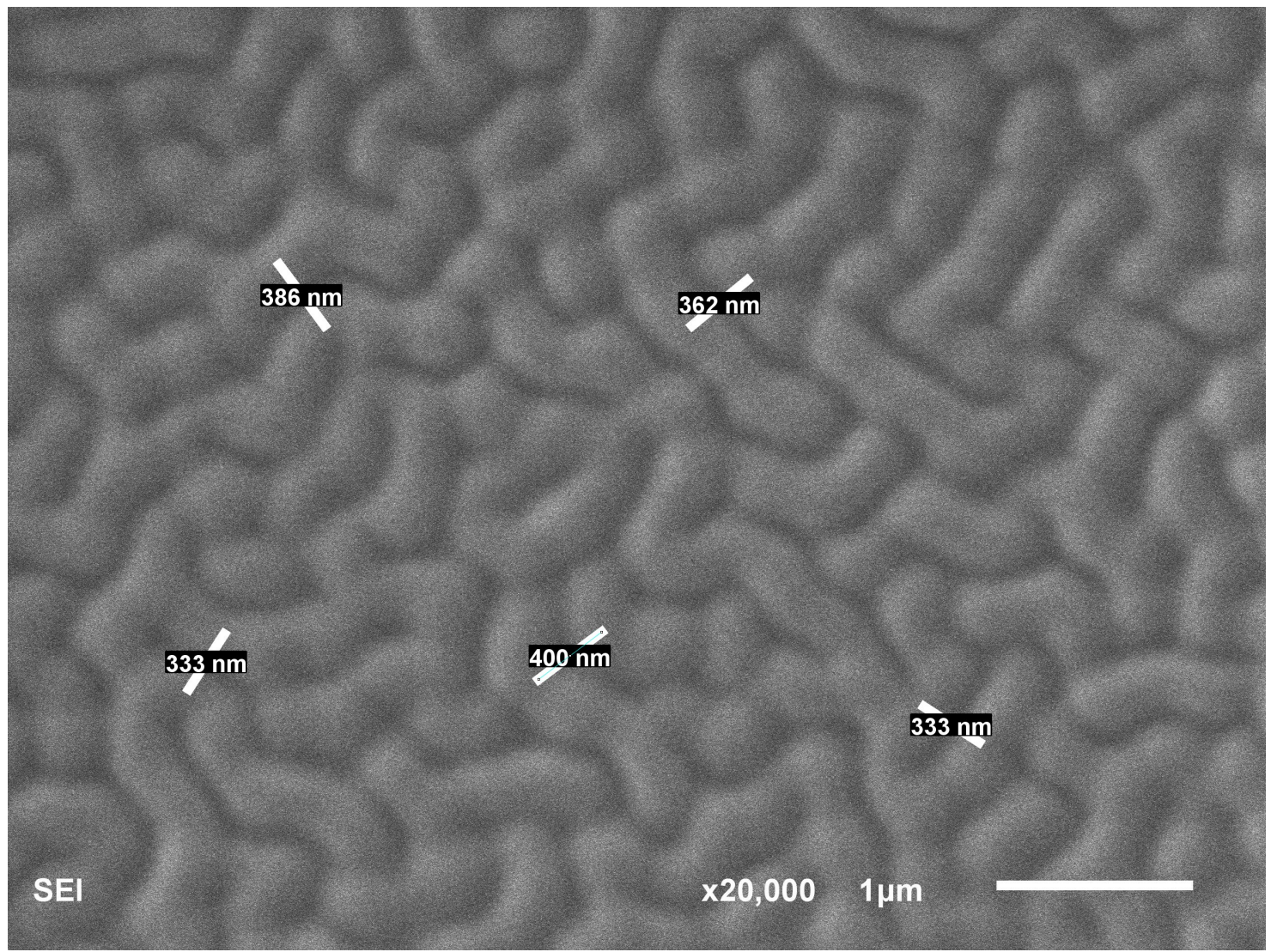

Figure S1: A representative image illustrating the estimation of wrinkling wavelengths based on 5 measurements at different positions. 